eyes prominent and inverted, I proposed to him that he should undergo an operation, when he told me that he had done so already. On examining his eye, the one which had been operated upon, I found it full, fixed, and prominent, and also inverted, and yet the patient had not the power of concealing any portion of its cornea, showing that the inner rectus muscle had been divided. 'This patient refused to submit to an operation on the opposite eye, which I have no doubt would have been attended with success, provided not only its muscle had been divided, but also its cellular tissue and fasciæ, to the same extent as had been done for its fellow. When I last saw him he was a living evidence of the abuse of an otherwise good and salutary operation.

12, Argyle-street, Feb. 27, 1841.

\section{CONTRIBUTIONS TO THE PATHOLOGY OF CHILDREN.}

BY P. HENNIS GREEN, M.B.

Lecturer on Diseases of Children, at the Hunterian School of Medicine. (Continued from page 294.)

SOFTENING OF THE SPINAL MARROW.

Diseases of the spinal marrow are excessively rare in children. Even tubercular affections, which prevail to such an extent in the brain, are hardly ever met with in this portion of the cerebro-spinal system. The following cases may therefore afford some interest, as examples of a disease which rarely presents itself to the practitioner; and from this circumstance, as well as the obscurity of many symptoms accompanying it, might readily be mistaken for one of a less serious nature.

CASE I.-J. W., 10 years of age, had made a very long journey, partly on foot and partly in a rough carriage. Soon afterwards (Oct. 10th) the child was seized with rigors, fever, and pains along the limbs. On the 11 th and 12 th she vomited frequently, and had some bleeding from the nose. On the evening of the 13th she complained of severe pain about the shoulder and hands, but no signs of any rheumatic affection could be discovered. 'The pains soon disappeared, but returned again, and the bowels were now obstinately constipated.

16. On admission into hospital, the only remarkable symptom observed was a considerable difficulty of breathing, without any physical signs of an inflammatory disease within the chest ; pulse 126 ; respiration 44 ; on moving the body or limbs the child complained of great pain; the bowels had been confined for several days; there was no headache or alteration of the intellectual faculties; no lesion of the senses, or other symptom of any serious disease within the skull.

17. The pain is now confined exclusively to the arms and legs; the respiration is still embarrassed and difficult, but sounds clear on auscultation; pulse 96 . On examining the abdomen a large mass of fæcal matter was found collected at the sigmoid flexure of the colon; but the abdomen is not tender on pressure. The patient was ordered to have two ounces of castor oil, at once, to be followed by a purgative enema; and five grains of Dover's powder, at night.

18. The hands and forearms are almost insensible; on the right side the fingers have nearly lost the power. of motion; on the left the limb is completely paralysed; the patient complains of acute pain in both shoulder-joints, but no tumefaction or redness can be discovered about them; the respiration is now much quicker, more impeded, and panting, than it was, but still the chest sounds clear on percussion, and no abnormal râle can be heard; the child's intellect is perfectly collected; no convulsive movements; pulse 96 ; respiration 60 . Twenty leeches were applied to the spine, and the limbs were rubbed with an opiate liniment. The local abstraction of blood, however, seemed to have no effect whaterer on the disease; the repiration became more and more impeded; the body and trunk became quite stiff, and the child died on the evening of the following day, in a state of apparent asphyxia, but having preserved her intellectual faculties unimpaired, almost to the last hour of existence.

\section{Body examined 30 hours after Death.}

Heal : The vessels of the pia mater on the upper sur face of the brain are considerably injected, as are also those distributed through its cortical and medullary substances; the nervous tissue, however, preserves its normal degree of consistency. There is no effusion of serum into the great cavity of the arachnoid, or the ventricles, nor any signs of inflammation.

Spinal Marrow: Arachnoid transparent; vessels of pia mater injected; the central part of the cervical portion of the spinal marrow is remarkably softened; at the dorsal region the softening occupies rather the external surface; but from the dorsal region down to the termination of the spinal marrow, the whcle thickness of the chord is extremely soft, and, at the same time, of a reddish or pink colour. The organs contained in the thoracic and abdominal cavities are remarkably healthy.

CASE II.-E. W., 8 years of age, sister of the patient whose case has been just related, was seized on Nov. 17 (the evening before the death of her sister) with a sense of numbness in the upper and lower extremities, and some pain along the spinc. The child, however, was sent to school as usual; but soon after her arrival there, she fell to the ground in a state of insensibility, attended with some convulsive motions, and stiffness of the limbs. She was immediately brought home, and a medical man sent for, who applied twenty leeches to the anus; the child now recovered the power of speech, but her other symptoms remained unchanged.

After a lapse of three weeks she was brought to the children's hospital, when the following symptoms were noted:-the intellectual faculties are not disturbed; the senses of sight, hearing, and taste, are perfect; pupils natural ; no squinting or distortion of the face; the left arm is strongly contracted; the movements of the shoulderjoint on this side are free, but those of the elbow-joint are abolished; the legs are semi-flexed, contracted, and the patient complains of severe pains in them. The fingers, also, of both hands are semi-flexed, and the child is scarcely able to squeeze anything between them. She is unable to sit up in bed, and complains of severe pain in the lumbar region of the spine whenever she is moved; pulse full, 120 ; respiration free, not accelerated; the bowels are confined, and she passes her urine under her in bed. Twelve leeches were applied over the painful part of the spine; and on the following day some more blood was drawn by cupping. By the abstraction of blood the symptoms werc slightly alleviated, and the child was shortly afterwards taken away from the hospital by her friends.

During the next six months the child continued in the same state, being constantly confined to bed, and unable to sit up, or use her hands or arms; various remedies were employed; leeches were frequently applied over the region of the spine, and blisters were placed on different parts of it; the limbs were rubbed with stimulating liniments, \&c.

At the end of the half year the patient was a little improved; she could sit up in bed; was free from pain, and could move her limbs slightly; she could also retain her evacuations.

On Nov. 12th, 1834, she was again admitted into hospital; her general appearance was now greatly improved, but the limbs were still contracted; there was no lesion of sensibility; no curvature of the vertebre; she could now feed herself, but was unable to put out one leg before the other. The pain in the back had disappeared; pulse and respiration regular; abdomen free from pain ; bowels constipated. Moxas were applied at cach sile of the vertebral canal, and purgatives were ocencionally administered.

On the teith day after the an! 'ontion of the moxac the 
skin adjoining the ulcerated surfaces became violently inflamed, and the child complained of severe pain in the region of the spinal marrow, extending to the upper and lower limbs; she cried constantly from the pain; the pulse became quick, and the skin hot. The local irritation was soon subdued by soothing treatment; but the contracture with paralysis remained; and the child being again removed from the hospital, was ultimately lost sight of.

London, Feb. 20, 1841.

PROVINCIAL

\section{SATURDAY, MARCH 6, 1841.}

It has been the practice of the Provincial Medical Association to require from one of its members an annual retrospect of the progress of medicine, at each succeeding anniversary of the Association. The information which has thus been collected and preserved in the rolumes of the transactions, affords a valuable record of the activity and zeal which characterises the Association. At the eighth anniversary, held at Southampton, two of these retrospeets were delivered, - the one on medicine, by $\mathrm{Dr}$. Scott, of Literpool,-the other on surgery, by Mr. Dodd, of Cbichester; - both of which are admirable digests of the increase to our knowledge obtained in their respective departments during the preceding year. Many advantages attend this practice: an annual record of the progress of medicine is regularly drawn up ; the more useful and im. portant discoreries are from time to time recorded; the information dispersed throughout the publications of different couritries is collected together into one focus; that which is truly valuable, atid likely to be of permanenit utility, sifted out from the mass of epliemeral and less instructive matter, amidst which it might otherwise remain concealed. A classified summary of the heads of this more valuable information is obtained, and an indicial synopsis is cothstructed, by wieh the student, or the practitioner immiuted in the daily calls of a laborious and extensive profession, is at once directed to what is really worthy of attention in the numerous periodical and other publications; much time and labour being thus saved in refering to wotks, some of them probably not immediately at hand; and frequetitly a fruttless search through pages and volumes atvided.

In the present day, when 80 many are actively occupied in intelleetual purstuits, some such periodical record of the progress of knowledge seems absolutely hecessary to enable the student to keep pace with the rapid advatice of the age. The chatacteristic of the times is active, restless, unceasing effort in an onward course. Grass no longer grows beneath the feet, either in a literal or a metaphorical sense. Everty effort which is made, in whaterer department of seietice, literature, or att, is quiékly followed by others in advance. The universal cry is-Forward! and he who fails in otie step is quickly thrown out of the coürse, with searcely the prospect of regaining the vantage-ground which he has lost; even by the most strenuous atid unremitting endearours. No individual, whaterer may be his thirst for information, howeveir etixtensire his capacity, however ardent his pursuit, can for one moment hope to attain to the knowledge of all human acquirement. Fortunate, indeed, will he be if, in working out his way, bis steps are guided towards some point of eminence, whence he may obtain a clear view of that which lies immediately before him. A division of labour is, therefore, of equal advantage in the pursuit of knowledge as in the practice of mechanical arts. There is, however, an important distinction to be drawn, in that each fresh accession to the store of intellectual truth brings the acquirement of the principles on which all science is based more within the power and grasp of the mind. Evety addition of wellobserved facts must necessarily tend to the establishment of those higher generalizations which we term laws of nature, and upon the due establishment and comprehension of which the principles of all knowledge must be founded. The details of science, or of any one of its so-called branches, are of incalculable, we had almost said infinite, extent, and must elude the powers of the most industrious and ardent to acquire. The principles upon which they are based, and the laws by which they are governed, are few and simple, and are within the reach of the earnest inquirer after truth. What is at present known resembles at best but a wide spread of shallow waters, the extent of which no man can compass, but the depth of which there are few who cannot fathom. A knowledge of the laws and initial principles of any department of science is only to be attained by the observation and study of innumerable facts, which crowd upon the attention at every step of our intellectual progress. Yet, at the same time, that the difficulty of becoming acquainted with these facts necessarily keeps pace with every increase made to their number, the power of comprehending them, and of developing the laws by which they are governed, is in a corresponding degree adranced. We may take an instance from the administration of remedial agents. Ipecacuanha has an emetic, a purgatire, an expectorant, a diaphoretic, or a tonic effect, according to the dose and state of combination in which it is giren; but before these its varied powers and uses could have been ascertained, so as to admit of their simple enunciation, it was requisite that a vast number of facts should be observed, collected together, and weighed. Much disappointment was doubtless often experienced in the employment of the remedy. By some it was probably rejected, as not fulfilling the object for which it had been extolled; by others, set aside as uncertain in its effects, or proscribed as positively injurious. It is now no longet necessary to go over the same ground. The observations made, at the expense of considerable time and labour, and the apparent discrepancies amongst them, have been reduced to the generalization, that a variation in the dose of the agent produces a variation in its effects; and the general fact is established, that ipecacuanha ranks either as an emetic, a cathartic, or a tonic, according to the quantity in which it is given. But by applying the same principles to observations made upon other therapeutic agents, a similar conclusion may be drawn; and hence a higher or more extended generalization is inferred, and the law established, that remitlial agents, or medicines, probduce different effects, actording to the doses in which they are administered. This is now well understood by every tyro in the profession; but it expresses the result of years of observation, and could only have been accurately deduced from much close and careful comparison. The application of reasoning of this description to a sufficient number of diligently observed and well-ascertained facts, constitutes the process of induction; and to the neglect of it, or to its 